\title{
Cancer fighting cancer: synthesis of the new heterocyclic system diimidazo-[1,2-a:1,2-c]-pyrimidine ${ }^{1}$
}

\author{
Aldo Andreani, ${ }^{a}{ }^{a}$ Massimiliano Granaiola, ${ }^{a}$ Alberto Leoni, ${ }^{a}$ Alessandra Locatelli, ${ }^{a}$ Rita \\ Morigi, ${ }^{a}$ Mirella Rambaldi, ${ }^{a}$ Gianluca Giorgi ${ }^{b}$, and Laura Salvini ${ }^{b}$ \\ ${ }^{a}$ Dipartimento di Scienze Farmaceutiche, Università di Bologna, Via Belmeloro 6, 40126 \\ Bologna, Italy, and ${ }^{b}$ Centro Interdipartimentale di Analisi e Determinazioni Strutturali, \\ Università di Siena, Via Aldo Moro, 53100 Siena, Italy \\ E-mail: aldo.andreani@unibo.it
}

Dedicated to Mimmo on his $70^{\text {th }}$ birthday

(received 25 Sep 02; accepted 03 Nov 02; published on the web 11 Nov 02)

\begin{abstract}
One of our projects devoted to the synthesis of potential antitumor agents is called "Cancer Fighting Cancer". This brought us to synthesize the new heterocyclic system, diimidazo-[1,2a:1,2-c]-pyrimidine, which is a key intermediate for the synthesis of antitumor derivatives. The structure of this compound was demonstrated by means of NMR and MS experiments.
\end{abstract}

Keywords: Diimidazo-[1,2-a:1,2-c]-pyrimidine, spectroscopy, NOE, anticancer activity

\section{Introduction}

In 1977 we published our first paper on the synthesis of potential antitumor agents. ${ }^{2}$ The last one (number 32 of this series) has been published recently. ${ }^{3}$ We called one of our projects, "Cancer Fighting Cancer" implying our search for molecules wherein a well known pharmacophoric group is duplicated. We envisioned such two-weaponed drugs as fighting cancer like a crab fights off enemies with its nippers.

The first fighter we designed for this project had the structure reported in Figure 1.

For the synthesis of this compound, 2,7-disubstituted di-imidazo-[2,1-b:1,2-d]-[1,3,4]-thiadiazole (compound 5 in Figure 2) was the key intermediate which we endeavored to prepare from 2,5diamino-1,3,4-thiadiazole 1. ${ }^{4}$ Since the reaction with excess of bromoketone did not give the expected results, we analyzed the reaction step by step: one equivalent of 2-bromoacetophenone gave the expected 2-amino-6-phenylimidazo-[2,1-b]-[1,3,4]-thiadiazole (3, R=phenyl) ${ }^{5}$ via the intermediate 2 , whereas reaction of 3 with additional 2-bromoacetophenone under several experimental conditions did not occur 
at the nitrogen in position 3 , but instead reacted at position 7 . Thus, instead of the expected compound 4, we obtained a salt which was characterized as 2-amino-7-(2-oxo-2-phenylethyl)-6phenylimidazo-[1,2-d]-[1,3,4]-thiadiazolium bromide 6 ( $\mathrm{R}=$ phenyl) by means of spectroscopic data and X-ray crystallography.

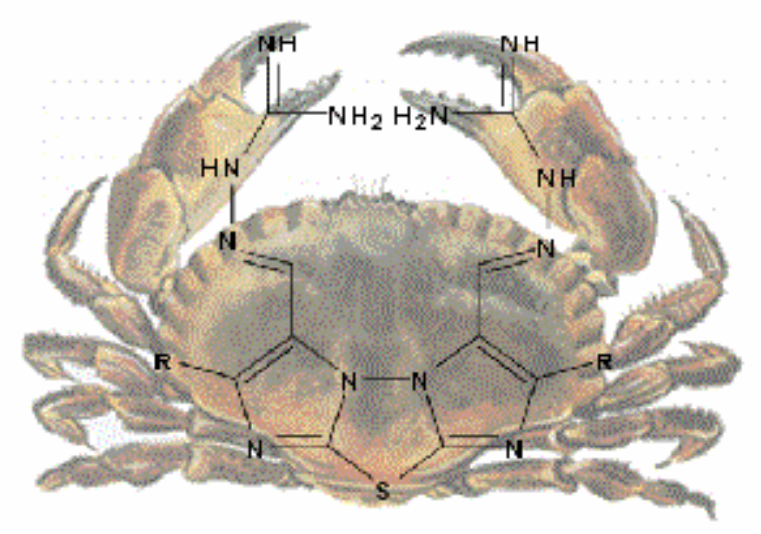

\section{Figure 1}

On the other hand, starting from 2,4-diaminopyrimidine we were able to prepare the intermediate for our first target compound, as illustrated in Figure 4.

\section{Chemistry}

The crystal structure of compound 6 ( $\mathrm{R}=$ phenyl) is depicted in Figure 3 . It has allowed us to unambiguously identify and structurally characterize the product of the reaction of $\mathbf{3}$ ( $\mathrm{R}=$ phenyl) with 2-bromoacetophenone.

Two independent molecules of $\mathbf{6}$ form the asymmetric unit. In the thiadiazole moiety the bond lengths are close to that found in analogous derivatives. ${ }^{6}$ As an example, the distance $\mathrm{N}-\mathrm{N}$ is equal to $1.396(9)$ and $1.379(8) \AA$ in the two molecules of the asymmetric unit The planar imidazothiadiazole ring and its appended phenyl group form dihedral angles of 39.1 and $43.2^{\circ}$, respectively, in the two molecules of the asymmetric unit. The phenyl bound to the $\mathrm{CH}_{2}-\mathrm{CO}$ group is close to being orthogonal to the imidazothiadiazole ring, with dihedral angles equal to 75.26 and $71.40^{\circ}$ in the two molecules of the asymmetric unit.

The crystal structure is stabilized by intermolecular hydrogen bonds and stacking interactions. One of these latter involves the thiadiazole moiety of one molecule and the phenyl ring bound at position 6 of the other molecule of the asymmetric unit. The distance between the two ring centroids is $3.61 \AA$, while the dihedral angle between the two planes is $11^{\circ}$. The mean distances between the amino groups and bromines $(\mathrm{N} . . \mathrm{Br})$ are $3.37 \AA$.

The reaction of 2,4-diaminopyrimidine, 7, with 2-bromoacetophenone (Figure 4) could afford three different compounds: 2-phenylimidazo-[1,2-a]-pyrimidin-7-amine, 8, 2phenylimidazo-[1,2-c]-pyrimidin-5-amine, 9, and 2-phenylimidazo-[1,2-a]-pyrimidin-5-amine, 10. 


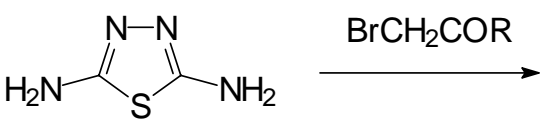<smiles>[R]C(=O)Cn1nc(N)sc1=N</smiles>

1<smiles>[R]c1cn2nc(N)sc2n1</smiles>

3

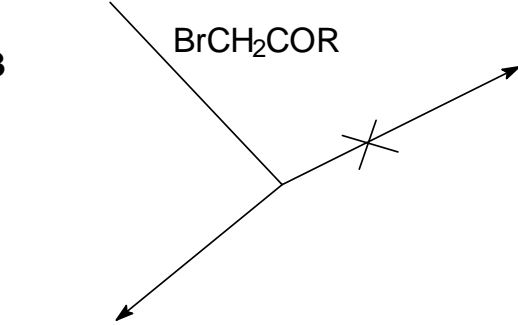<smiles>[R]C(=O)Cn1c(=N)sc2nc([R])cn21</smiles>

4

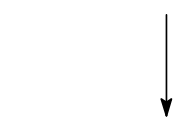<smiles>[R]C(=O)CN1N=CN2N=C(N)SC21</smiles><smiles></smiles>

5

6

\section{Figure 2}

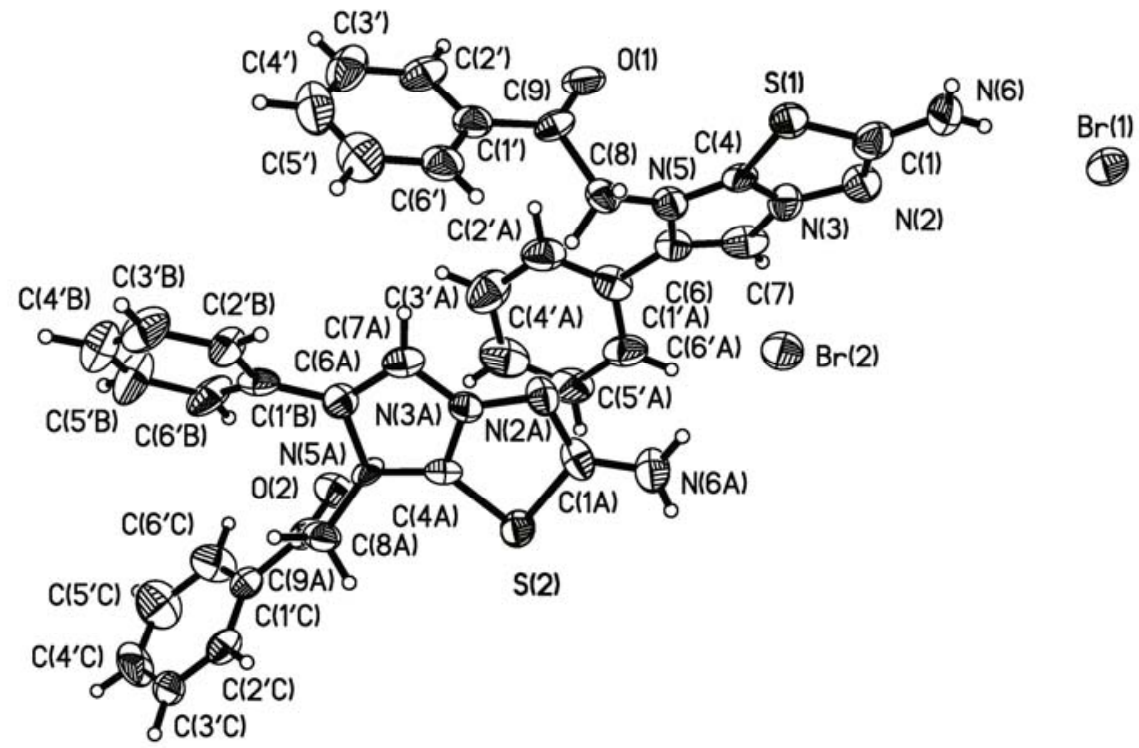

Figure 3. Drawing of the asymmetric unit of compound 6 with the labeling of the atoms. The non $\mathrm{H}$-atoms ellipsoids enclose $50 \%$ probability. 


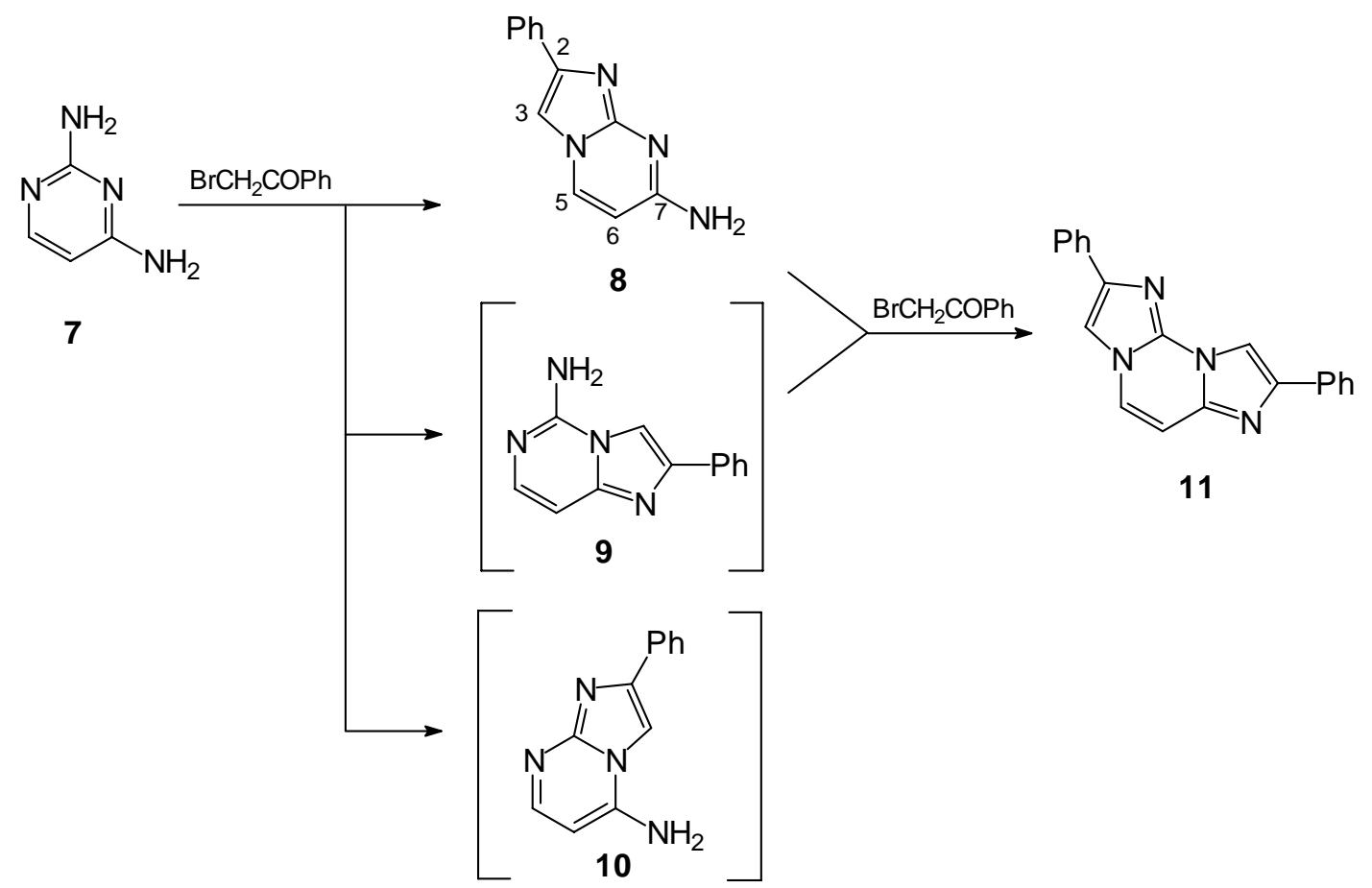

\section{Figure 4}

Under the conditions described in the Experimental Section we isolated one compound only, which when treated again with 2-bromoacetophenone gave a new heterocyclic system. The structure of 2,8-diphenyldiimidazo-[1,2-a:1,2-c]-pyrimidine, 11, was confirmed by means of spectroscopic data. Compound 11 may arise from both $\mathbf{8}$ and 9, but not from 10. The product of the reaction between $\mathbf{7}$ and 2-bromoacetophenone was $\mathbf{8}$, as confirmed by NOE experiments. The irradiation of the amino group $(6.83 \mathrm{ppm})$ gave NOE at $6.25 \mathrm{ppm}$, i.e., at the nearest pyrimidine hydrogen (H-6). As a consequence the doublet at $8.36 \mathrm{ppm}$ was assigned to the $\mathrm{H}-5$ pyrimidine and its irradiation gave NOE at $6.25 \mathrm{ppm}(\mathrm{H}-6)$ and at the imidazole proton $(\mathrm{H}-3,7.83 \mathrm{ppm})$.

An attempt to prepare 11 directly from 7 with excess of 2-bromoacetophenone was unsuccessful: the intermediate $\mathbf{8}$ is formed as the hydrobromide and it was necessary to prepare the corresponding base before treating it again with 2-bromoacetophenone.

\section{Conclusions}

Compound 11 was then functionalized in order to obtain bis-weaponed molecules, analogous to that reported in Figure 1. The first of those derivatives was submitted to the National Cancer Institute (Bethesda, MD) with the NSC number 720134. It was active in the panel of three human tumor cell lines and is now under evaluation in the full panel of sixty cell lines. ${ }^{7}$ 
The chemistry of this compound will be published as soon as the biological data are available.

\section{Experimental Section}

General Procedures. Melting points are uncorrected. Analyses $(\mathrm{C}, \mathrm{H}, \mathrm{N})$ were within $\pm 0.4 \%$ of the theoretical values. Bakerflex plates (silica gel IB2-F) were used for TLC: the eluent was petroleum ether/acetone 50/50. The IR spectra were recorded in Nujol on a Nicolet Avatar 320 E.S.P.; $v_{\max }$ is expressed in $\mathrm{cm}^{-1}$. ${ }^{1} \mathrm{H}-\mathrm{NMR}$ spectra were recorded in $\left(\mathrm{CD}_{3}\right)_{2} \mathrm{SO}$ on a Varian Gemini (300 MHz); the chemical shift (referenced to solvent signal) is expressed in $\delta(\mathrm{ppm})$ and $\mathrm{J}$ in $\mathrm{Hz}$ with the following abbreviations: ar=aromatic, pym=pyrimidine, im=imidazole. $\mathrm{MS}$ and MS/MS spectra were obtained by using a ThermoFinnigan LCQDeca instrument operating with electrospray ionization.

2-Amino-7-(2-oxo-2-phenylethyl)-6-phenylimidazo-[1,2-d]-[1,3,4]-thiadiazolium bromide (6) $(\mathbf{R}=$ phenyl). Compound $3(14 \mathrm{mM})$ was dissolved in acetone $(50 \mathrm{~mL})$, treated with 2bromoacetophenone $(16 \mathrm{mM})$, and heated at reflux for $3 \mathrm{~h}$. The resulting precipitate was collected by filtration and crystallized from ethanol with a yield of $73 \%$. Analogous results were obtained with different solvents $\left(\mathrm{EtOH}, \mathrm{CH}_{3} \mathrm{CN}, \mathrm{CHCl}_{3}\right.$, THF, with or without catalytic amounts of $\mathrm{AcOH}$ or $\mathrm{CF}_{3} \mathrm{COOH}$ ) and different reaction times. White crystals m.p. $235-240^{\circ} \mathrm{C}$ dec. Calcd. for $\mathrm{C}_{18} \mathrm{H}_{15} \mathrm{BrN}_{4} \mathrm{OS}$ : (415.3) C, 52.06; H, 3.64; N, 13.49. Found: C, 52.35; H, 3.60; N, 13.51\%. IR: 3227, 3053, 1696, 1618, 1532, 1234, $764 \mathrm{~cm}^{-1} .{ }^{1} \mathrm{H}-\mathrm{NMR}: \delta .6 .15$ (2H, s, $\left.\mathrm{CH}_{2}\right), 7.49$ (5H, m, ar), $7.58(2 \mathrm{H}, \mathrm{t}, \mathrm{ar}, \mathrm{J}=8), 7.74(1 \mathrm{H}, \mathrm{t}, \mathrm{ar}, \mathrm{J}=8), 7.98(2 \mathrm{H}, \mathrm{d}, \mathrm{ar}, \mathrm{J}=8), 8.44\left(2 \mathrm{H}\right.$, broad s, $\left.\mathrm{NH}_{2}\right), 8.61$ $(1 \mathrm{H}, \mathrm{s}, \mathrm{im})$.

X-ray crystallography of $\mathbf{6}(\mathbf{R}=$ phenyl). Single crystals of $\mathbf{6}$ were obtained by dissolving some $\mathrm{mg}$ of powder in EtOH and allowing the solution to evaporate at room temperature. A Siemens

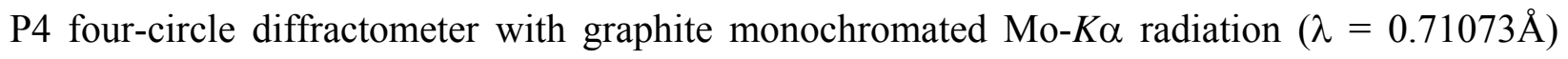
and the $\omega / 2 \theta$ scan technique were used for data collections. The structure was solved by direct methods implemented in the SHELXS-97 program. ${ }^{8}$ The refinement was carried out by fullmatrix anisotropic least-squares on $\mathrm{F}^{2}$ for all reflections for non-H atoms by using the SHELXL97 program. ${ }^{9}$ Crystal data are reported in Table 1. 
Table 1. Crystal data for 6 ( $\mathrm{R}=$ phenyl)

\begin{tabular}{|c|c|}
\hline Formula & $\mathrm{C}_{18} \mathrm{H}_{14} \mathrm{~N}_{4} \mathrm{OS} \times \mathrm{HBr}$ \\
\hline M & 415.31 \\
\hline Crystal size/(mm) & $0.2 \times 0.2 \times 0.4$ \\
\hline Crystal System & Monoclinic \\
\hline Space Group & $\mathrm{P} 2{ }_{1} / \mathrm{c}$ (n. 14) \\
\hline$a / \AA$ & $13.539(2)$ \\
\hline$b / \AA$ & $10.228(1)$ \\
\hline$c / \AA ̊$ & $26.787(5)$ \\
\hline$\beta /^{\circ}$ & $102.09(1)$ \\
\hline $\mathrm{U} / \AA^{3}$ & $3627.1(9)$ \\
\hline Temperature /K & $293(2)$ \\
\hline $\mathrm{Z}$ & 8 \\
\hline $\mathrm{F}(000)$ & 1680 \\
\hline $\mathrm{D}_{\mathrm{c}} / \mathrm{g} \mathrm{cm}^{-3}$ & 1.521 \\
\hline$\mu\left(\mathrm{Mo}-K_{\alpha}\right) / \mathrm{mm}^{-1}$ & 2.4 \\
\hline Scan mode & $\omega / 2 \theta$ \\
\hline Scan range $/^{\circ}$ & $1 \leq \theta \leq 25$ \\
\hline Scan width/ ${ }^{\circ}$ & 1.18 \\
\hline Scan speed ${ }^{\circ} \min ^{-1}$ & 3 \\
\hline Independent reflections & 6374 \\
\hline Obs. reflections $(I>2 \sigma(I))$ & 2564 \\
\hline N. parameters refined & 455 \\
\hline $\mathrm{R}_{1}(I>2 \sigma(I))$ & 0.0755 \\
\hline $\mathrm{wR}_{2}(I>2 \sigma(I))$ & 0.1261 \\
\hline
\end{tabular}

Synthesis of 2-phenylimidazo-[1,2-a]-pyrimidin-7-amine (8). 2,4-Diaminopyrimidine 7 (10 $\mathrm{mM}$ ) was dissolved in $40 \mathrm{~mL}$ of acetone and treated with 2-bromoacetophenone (15 mM). The reaction mixture was refluxed for $3 \mathrm{~h}$ and the resulting precipitate (8, hydrobromide) was collected by filtration. The free base was obtained by treatment with $15 \% \mathrm{NH}_{4} \mathrm{OH}$. The resulting precipitate was collected by filtration and crystallized from ethanol with a yield of $90 \%$. White crystals m.p. $240-242^{\circ} \mathrm{C}$ dec. Calcd. for $\mathrm{C}_{12} \mathrm{H}_{10} \mathrm{~N}_{4}$ : C, 68.56; H 4.79; N, 26.65. Found: $\mathrm{C}, 68.23$; $\mathrm{H}, 4.60$; N, 26.87\%. IR: 3466-3126, 1650, 807, $717 \mathrm{~cm}^{-1} .{ }^{1} \mathrm{H}-\mathrm{NMR}: 6.25(1 \mathrm{H}, \mathrm{d}$, pym-6, J=6.9), $6.83\left(2 \mathrm{H}, \mathrm{s}, \mathrm{NH}_{2}\right), 7.24(1 \mathrm{H}, \mathrm{t}, \mathrm{ar}, \mathrm{J}=7.3), 7.38(2 \mathrm{H}, \mathrm{t}, \mathrm{ar}, \mathrm{J}=7.3), 7.83(1 \mathrm{H}, \mathrm{s}, \mathrm{im}-3), 7.82(2 \mathrm{H}, \mathrm{d}$, ar, J=7.3), $8.36(1 \mathrm{H}, \mathrm{d}$, pym-5, J=6.9).

MS and MS/MS (ESI): m/z $211[\mathrm{M}+\mathrm{H}]^{+}(100 \%), 169,115,91$.

Synthesis of 2,8-diphenyldiimidazo-[1,2-a:1,2-c]-pyrimidine, (11). Compound 8 (5 mM) was dissolved in ethanol $(40 \mathrm{~mL})$, treated with excess of 2-bromoacetophenone $(15 \mathrm{mM})$ and kept 
under reflux for $6 \mathrm{~h}$. The resulting compound $\mathbf{1 1}$ hydrobromide was collected by filtration and treated with $15 \% \mathrm{NH}_{4} \mathrm{OH}$ in order to prepare the free base which was collected by filtration and crystallized from ethanol with a yield of $25 \%$. White crystals m.p. $210-212^{\circ} \mathrm{C} \mathrm{dec}$. Calcd. for $\mathrm{C}_{20} \mathrm{H}_{14} \mathrm{~N}_{4}$ : C, 77.40; H, 4.55; N, 18.05. Found: C, 77.15; H, 4.84; N, 18.29. 310.36). IR: 1639, 1604, 1197, 778, $714 \mathrm{~cm}^{-1} .{ }^{1} \mathrm{H}-\mathrm{NMR}: 7.21(1 \mathrm{H}, \mathrm{d}$, pym, J=7.8), 7.33 (2H, t, ar, J=7.2), 7.46 (4H, m, ar), $7.94(2 \mathrm{H}, \mathrm{d}, \mathrm{ar}, \mathrm{J}=7.2), 8.08(2 \mathrm{H}, \mathrm{d}$, ar, J=7.2), $8.25(1 \mathrm{H}, \mathrm{s}, \mathrm{im}), 8.30$ (1H, d, pym, J=7.8), 8.75 (1H, s, im). MS and MS/MS (ESI): m/z $311[\mathrm{M}+\mathrm{H}]^{+}(100 \%), 284,257,208,181$.

\section{Acknowledgements}

We are grateful to the National Cancer Institute (Bethesda, MD) for the antitumor tests.

\section{References}

1. Potential antitumor agents 33. For part 32, see ref. 3.

2. Andreani, A.; Rambaldi, M.; Bonazzi, D.; Filippeschi, S.; Pintus, C. Boll. Chim. Farm. 1977, 116, 370.

3. Andreani, A.; Granaiola, M.; Leoni, A.; Locatelli, A.; Morigi, R.; Rambaldi, M.; Garaliene, V. J. Med. Chem. 2002, 45, 2666.

4. Fromm, E. Annalen Liebigs 1923, 433, 1.

5. Sitte, A.; Paul, H.; Hilgetag, G. Z. Chem. 1967, 7, 341.

6. Antolini, L; Cornia, A; Fabretti, A.C.; Malavasi, W. J. Crystallogr. Spectrosc. Res. 1993, 23, 967.

7. Monks, A.; Scudiero, D.; Skehan, P.; Shoemaker, R.; Paull, K.; Vistica, D.; Hose, C.; Langley, J.; Cronise, P.; Vaigro-Wolff, A. J. Natl. Cancer Inst. 1991, 83, 757.

8. Sheldrick, G.M. SHELXS-97, Rel. 97-2, Universität Göttingen, 1997.

9. Sheldrick, G.M. SHELXL-97, Rel. 97-2, Universität Göttingen, 1997. 